\title{
The Exploration of the Intangible Cultural Heritage of the Leisure Sports for Ethnic Minorities in Sichuan
}

\author{
Yu Mingrong, Yang Jun \\ Sichuan Agricultural University Sports College, Yaan, 625000, China
}

Keywords: Ethnic minority; Leisure sports; Minority nationality

\begin{abstract}
Sichuan has rich intangible cultural heritage of minority leisure sports. Under the background of economic globalization and urbanization in China, the crisis of the inheritance of intangible cultural heritage of Sichuan minority leisure sports has three points. First, the hollowing out of the ethnic minority areas in Sichuan led to the loosening of the foundation of national traditional sports; secondly, the sense of identity of the intangible cultural heritage of national leisure sports was reduced; thirdly, the impact of modern fitness and entertainment methods on national leisure sports was intensified. In the face of difficulties, the intangible cultural heritage of Sichuan national leisure sports can be explored based on the local government, ethnic villages and intangible cultural heritage inheritors. In the excavation of the intangible cultural heritage of leisure sports in Sichuan, the intangible cultural heritage of ethnic minorities should be classified according to the characteristics of the intangible cultural heritage of Sichuan minority leisure sports, according to martial arts and festival folklore.
\end{abstract}

\section{Introduction}

With the impact of the globalization of the world economy and the diversification of culture, the intangible cultural heritage containing the essence of Chinese civilization has been seriously threatened. The traditional sports culture of ethnic minorities has become increasingly difficult due to the aging of inheritors. Numerous intangible cultural heritages are facing extinction [1]. Sichuan Province has 4 UNESCO non-legacy projects (Year, Gesar, Jinjin, Phi Phi), 139 national non-legacy projects, and 522 provincial-level projects, including non-material culture of minority sports at or above the provincial level. There are 33 estates. Although the intangible cultural heritage of minority sports in Sichuan Province has achieved some results, the development of intangible cultural heritage of traditional sports of ethnic minorities still faces enormous challenges, and it is extremely urgent to dig and organize.

\subsection{The hollowing out of the population in ethnic minority areas has led to the loosening of the foundation for the development of national intangible cultural heritage.}

The hollowing out of the rural population refers to the large inflow of young and middle-aged laborers into the cities, resulting in a decline in the rural population and a decline in the proportion of rural young and middle-aged population. The majority of the rural population is elderly, women and children [3]. Sichuan Province is located in the hinterland of southwest China. It has a vast territory and a large population. It is a large province with a large population and a large agricultural province. Most of the intangible cultural heritage of ethnic minority leisure sports in Sichuan originated from ethnic minority villages. With the acceleration of urbanization and the further development of China's economy, the number of migrant workers in Sichuan's young and middle-aged labor increased sharply, and the rural population structure was unbalanced, leading to leisure. The foundation of the intangible cultural heritage of the sports nation is loosened, and the family inheritance and national inheritance of the national intangible cultural heritage are in crisis.

\subsection{The contradiction between modern culture and traditional culture leads to a decrease in the sense of national identity.}

The concept of nationality is based on the nation, the nation, and the nation as the starting point. 
It explores a theoretical concept of thinking about the political, economic, military, and artistic aspects of the whole world, with a relatively stable view and proposition of the entire nation. There are as many as 12 items involving religious and ethnic beliefs in the intangible cultural heritage of ethnic minority leisure sports. For example, the fire dragon dance of the ancient intangible cultural heritage of Huanglongxi and the Chenzhou Yutan Cailong have significant national beliefs. The fire dragon dance and the rain-colored dragon are held to pray for the good weather, the grain, and the evil spirits. With the progress of society, the majority of the younger generation is no longer engaged in traditional agricultural work, and the gradual weakening of their national beliefs has led to low enthusiasm for participating in sports intangible cultural heritage projects.

\subsection{The impact of modern fitness and entertainment methods on national leisure sports}

Traditional folk leisure sports is one of the origins of the development of national leisure sports. For example, Tibetan chess, Tibetan Ursu archery, Yi people's autumn, Sanxiong wins, Yi people putt, slippery sisters, crowbars and other sports intangible cultural heritage originated from traditional folk entertainment games in ethnic areas. According to statistics, there are 33 intangible cultural heritages of leisure sports in Sichuan Province, including 7 games and entertainments. It can be seen that the leisure activities of ancient laborers are an important channel for the formation of sports intangible cultural heritage. With the advancement of reform and opening up, modern entertainment such as television, internet, electronic game consoles, ballroom dancing, and square dances have continuously entered the villages of ethnic minority areas in Sichuan. The relatively closed and backward ethnic areas have begun to be influenced by modern civilization. Many residents gradually abandoned the ancient traditional entertainment projects, especially as more and more teenagers began to choose modern fitness and entertainment methods, which made the local national sports intangible cultural heritage project suffer a strong impact.

\section{Excavation Path and Form of Intangible Cultural Heritage of Sichuan Minority Leisure Sports}

Sichuan has a long history of multi-ethnic sports intangible cultural heritage. The development forms, activities and inheritance methods of the non-material cultural heritage projects of different sports are different. Therefore, the exploration of the intangible cultural heritage of leisure sports in Sichuan requires different paths and methods.

\subsection{Exploring the Intangible Cultural Heritage of Sichuan Minority Leisure Sports}

\subsubsection{Excavation through the inheritance of intangible cultural heritage}

A basic characteristic of intangible cultural heritage that differs from physical cultural heritage is that it exists in the individual, group or specific area or space attached to the individual, and is a "live" culture. Whether it is oral literature and language, traditional performing arts, traditional handicraft skills, traditional etiquette festivals, etc., it is closely related to the activities of individuals or groups of people (including display, performance and inheritance). As a kind of "live" culture, intangible cultural heritage needs to collect and preserve those material carriers, or form their materials through records and other means. More importantly, it is necessary to effectively protect those who master and express the outstanding intangible cultural heritage skills or forms, so that they can continue and develop in the present and future society through the inheritance of individuals, groups and nations.

\subsubsection{Respect the source and root the country.}

The cultural soil is the foundation of the inheritance of intangible cultural heritage, which provides genes and nutrients for the reproduction of intangible cultural heritage. The non-material sports culture of ethnic minorities is developed, developed, evolved and innovated in its unique cultural soil, with obvious geographical and national colors. As soon as each nation was born, it formed an indissoluble bond with the local natural environment. The local ecological environment is the mother that nurtures and nurtures various nationalities, and it is also the ecological soil for the 
intangible cultural heritage of minority leisure sports. The inheritance activities of the intangible sports cultural heritage of several ethnic groups generally do not deviate from the special production and lifestyle of the region and the nation, and are passed down from generation to generation in vivid and vivid form. To protect them, we should respect the origin of culture, let it root in the native land, develop its own national characteristics, and cannot easily transfer and destroy its most pure and simple emotional inheritance.

\subsubsection{Government-led, activating the intangible cultural heritage of sports.}

Through guidance and support, the Sichuan minority government has established a platform to attract more social funds and strength to help the popularization of the national traditional sports culture. It will integrate sports intangible cultural heritage with economy, culture, education, tourism and entertainment, activate the intangible cultural heritage of minority leisure sports, and build a good inheritance system of traditional sports culture of ethnic minorities. Taking the Xuantan Lion Dance as an example, the Xuantan Town Government issued a policy to issue special documents to protect and pass on the Xuantan Lion Dance. First, the town financed a special fund, and allocated 30,000 yuan each year for the protection and inheritance of the Xuantan Lion Dance, improving the representative living environment and the living space of the Xuantan Lion Dance. Second, using text, audio, video, digital multimedia and other means, real, systematic and comprehensive records of the Xuantan lion dance, the establishment of the Xuantan lion dance text file and database [4]. Third, systematically organize the performance routines, basic steps and paces of the Xuantan Lion Dance, and standardize the accompaniment percussion scores of the Xuantan Lion Dance. The series of guidance and protection measures of the Xuantan Town Government have enhanced the influence of the Xuantan Lion Dance and formed a distinctive brand effect.

\subsection{Excavation Forms of Intangible Cultural Heritage of Sichuan Minority Leisure Sports}

According to the characteristics of the project, the intangible cultural heritage of Sichuan minority sports can be divided into Wushu minority intangible cultural heritage and festival folk custom intangible cultural heritage. In the excavation of the intangible cultural heritage of leisure sports in Sichuan, the multi-form excavation should be carried out systematically and comprehensively. According to the characteristics of the intangible cultural heritage of leisure sports in Sichuan, different forms of excavation should be classified.

\subsubsection{Push the teaching materials and supplement the stage to promote the "healthy China" dream.}

The intangible cultural heritage of Sichuan ethnic minorities includes Emei Wushu, Qingcheng Wushu, Yu Menzhang, Emei Pan Breaking, Greenwood School Martial Arts and Li Yaxuan Taijiquan. Martial arts projects should make full use of the fitness, performance and martial arts of martial arts according to the characteristics of the project itself. First, the martial arts fitness, the basic pace (action) as the main content of the martial arts fitness routine teaching materials, the minority sports into the national fitness. National fitness is the development direction of mass sports in China, and it is the basic national policy for the development of sports in China. The traditional sports of ethnic minorities are included in the national fitness activities, and minority sports are likely to get the greatest development. Second, the stage of martial arts, the arranging of martial arts, adding to the development of the plot, let martial arts appear in the form of stage programs in front of the audience is an important way to improve the influence of martial arts. Third, the martial arts competition, holding martial arts competitions for the intangible cultural heritage of ethnic minority leisure sports, promoting martial arts cultural exchanges, and attracting more social resources to the development of intangible cultural heritage martial arts projects through the platform of competitions. It can also promote the promotion of minority non-material sports culture.

\subsubsection{Folklore as "boat", culturally dominant, and create brand effect.}

There are many ethnic minorities living in Sichuan, and the non-material cultural heritage of festival folk music is rich. In the existing project statistics, 12 national sports activities such as 
Yutan Rainbow, Fire Dragon Dance and Ban Le Lion are included in the provincial intangible cultural heritage Among them, Yutan Cailong and Fire Dragon Dance are selected as national intangible cultural heritage. The intangible cultural heritage of the minority sports of the festival has a strong national cultural characteristics, and there are many audiences during the festival. Nowadays, China's economy is developing at a high speed, and tourism has become an inevitable choice for people's "development needs." Natural landscapes, folk customs, and forms of sports activities together constitute ethnic minority sports, which are precisely the main factors that different groups consider when choosing. Therefore, we can incorporate festival folklore sports into the development of regional tourism resources, realize the win-win situation of tourism development and national sports protection, and develop our own national characteristics, and lead by culture to create one of our own cultural brands. The excavation form of sports intangible cultural heritage can be based on stage programs, forming rich performance works, performing in specific folk festivals or large-scale festivals, gradually forming intangible cultural heritage features, and creating outstanding works for national sports intangible cultural heritage. works.

\section{Conclusions}

Since the economic globalization and urbanization, the ecological environment inherited by the ethnic minority leisure sports in Sichuan has undergone dramatic changes. Modern production methods, lifestyles, education and entertainment methods have brought tremendous development to the national traditional sports. The challenge is that the living space of ethnic minority sports culture is severely squeezed in the confrontation with the process of social civilization. in the context of the continuous advancement of social civilization, how to explore traditional folk sports and protect the intangible cultural heritage of sports is particularly important. The intangible cultural heritage of leisure sports in Sichuan is rich, and the traditional sports culture of ethnic minorities is characterized by closure, productivity and religion. in the face of the change of social starring Liu Wenhua, the development of traditional sports of ethnic minorities must be reformed to meet the needs of today's people. First of all, the minority leisure sports non-material material culture project will be sorted out and promoted, so that it can be combined with mass fitness to expand the image of the project. Secondly, the government guides the intangible cultural heritage of ethnic minorities and tourism to form a distinctive tourism brand of intangible cultural heritage of ethnic minorities, promotes the industrialization of intangible cultural heritage of ethnic minority leisure sports, and attracts more social forces to participate in the intangible cultural heritage of ethnic minorities. Protection and inheritance.

\section{Acknowledgements}

2017 “Sichuan Provincial Key Research Base of Philosophy and Social Sciences”, 2017 "Key Research Base of Humanities and Social Sciences in Colleges and Universities of Sichuan Province".

Results of the research project of "Sichuan Leisure Sports Industry Development Research Center” in 2017.

Title: Research on the Excavation and Database Construction of Intangible Cultural Heritage of Sichuan Minority Leisure Sports.Subject Number: XXTYCY2017D06.

Research Project of Sichuan Sports Industry and Public Service Research Center in 2018

Subject Number: SCTV2018ZC07.

Research Project of Sichuan Sports Industry and Public Service Research Center in 2018.

\section{References}

[1] Chen Xiaorong, Resource Database Construction of China's Sports Intangible Cultural Heritage [J].Sports Culture Guide, 2013.8, No.8, 105-108

[2] Wang Dongming, Wang Ping, Liu Yong, Protection of the Intangible Cultural Heritage Life 
Style of Traditional Sports[J].Journal of Hebei North University,2016.8 Vol.32, No.2, 101-104

[3] Lu Avenue, Fan Ran, 2050: Regional Development in China: [M] Science Press, Beijing, 2010.123-124

[4] Sichuan Provincial Sports Bureau. Sichuan Sports Intangible Cultural Heritage [EB/OL]. (2017-12-19)[2018-02-15]Http://www.scsport.gov.cn/tywh/fy/index_1.html

[5] Wang Wen. An Overview of Intangible Cultural Heritage [M]. Beijing: Culture and Art Publishing House, 2010. 78-79 